\title{
Combat Exposure and Risk of Suicide Attempt Among Danish Army Military Personnel
}

\author{
Mia S. Vedtofte, $\mathrm{PhD}^{\mathrm{a}, *}$; Andreas F. Elrond, PhD ${ }^{\mathrm{a}}$; Annette Erlangsen, $\mathrm{PhD}^{\mathrm{b}, \mathrm{c}, \mathrm{d}}$; Anni B. S. Nielsen, $\mathrm{PhD}^{\mathrm{a}}$; \\ Christian D. G. Stoltenberg, MSc ${ }^{\mathrm{a}}$; Jacob L. Marott, MSc ${ }^{\mathrm{e}}$; Lars R. Nissen, MD ${ }^{\mathrm{a}}$; and Trine Madsen, $\mathrm{PhD}^{\mathrm{b}}$
}

\begin{abstract}
Objective: The aim of this study was to estimate the association between self-reported perceived danger during deployment, measured as combat exposure or witnessing the consequences of war, and post-deployment suicide attempts among military personnel. Furthermore, the effect of post-deployment symptoms of posttraumatic stress disorder (PTSD) and/or depression on the risk of suicide attempts was also evaluated.
\end{abstract}

Methods: This observational cohort study included Danish Army military personnel who returned from deployment in international missions from 1998 to 2016 and had completed a post-deployment questionnaire. Perceived exposure to danger was ascertained by self-report. Data on suicide attempt were retrieved from national registers. Adjusted Cox regression analyses were used to evaluate if military personnel indicating high level of combat exposure were more likely to have attempted suicides post-deployment than military personnel with lower levels of combat exposure.

Results: Eighty-three suicide attempts were registered after homecoming among 12,218 military personnel. Perceived higher exposure to combat was associated with the risk of suicide attempt (hazard ratio $=1.08 ; 95 \% \mathrm{Cl}, 1.01-1.16$ ). Furthermore, the association between combat exposure and suicide attempt was fully mediated by post-deployment symptoms of PTSD and/ or depression. No association was found between witnessing consequences of war and the risk of post-deployment suicide attempt.

Conclusions: This nationwide study found that combat exposure was associated with an increased risk of suicide attempt among military personnel. This association was, however, fully mediated by mental disorders (PTSD and/or depression). These findings suggest that better psychological follow-up of military personnel identified as having PTSD and/or depression may be warranted.

J Clin Psychiatry 2021;82(6):20m13251

To cite: Vedtofte MS, Elrond AF, Erlangsen A, et al. Combat exposure and risk of suicide attempt among Danish Army military personnel. J Clin Psychiatry. 2021;82(6):20m13251.

To share: https://doi.org/10.4088/JCP.20m13251

(c) Copyright 2021 Physicians Postgraduate Press, Inc.

${ }^{a}$ Research and Knowledge Centre, the Danish Veteran Centre, Ringsted, Denmark

${ }^{b}$ Danish Research Center for Suicide Prevention (DRISP), Copenhagen Mental Health Center, Copenhagen University Hospital, Copenhagen, Denmark

'Department of Mental Health, Johns Hopkins Bloomberg School of Public Health, Baltimore, Maryland

${ }^{d}$ Centre for Mental Health Research, Research School of Population Health, The Australian National University, Canberra, Australia

${ }^{e}$ Copenhagen City Heart Study, Frederiksberg Hospital, Frederiksberg, Copenhagen, Denmark

*Corresponding author: Mia Sadowa Vedtofte, PhD, Research and Knowledge Centre, The Danish Veterans Centre, Garnisonen 1, 4100 Ringsted, Denmark (Vetc-vic02@mil.dk).
A $\mathrm{n}$ increased prevalence of suicidal behavior among formerly deployed military personnel has been reported. ${ }^{1-4}$ It has been suggested that combat exposure is associated with an elevated risk of suicide, a suggestion supported by the high suicide rates reported after homecoming from the wars in Iraq and Afghanistan, where soldiers experienced high levels of combat exposure. ${ }^{5,6}$ However, the existence of this association has been debated, and combat exposure may be linked indirectly to suicidal behavior through mediation by posttraumatic stress disorder (PTSD) and depressive symptoms. Military personnel who screened positive for PTSD post-deployment have been found to be 4 times as likely to report suicidal ideation as their peers without PTSD. ${ }^{7}$ Furthermore, PTSD and depression have been found to co-occur. ${ }^{8}$

Military variables (eg, combat exposure, number of deployments) have been identified from large epidemiologic studies from the United States, such as the Millennium Cohort Study ${ }^{9}$ and Army Study to Assess Risk and Resilience in Service members (Army STARRS) ${ }^{10}$ but these studies have shown low associations with suicidal behavior. However, suicide risk factors have been identified from these studies, but they have either (1) not been unique to military suicide (social support, religious affiliation, psychological factors, and mental health treatment) or (2) been characteristic of the military so that they have minimal use in detecting risk (eg, young men). ${ }^{11}$

Thus far, a recent systematic review and meta-analysis ${ }^{12}$ (which comprised only 3 studies on this topic) concluded that the relationship between combat exposure and suicide attempt (SA) is still not fully understood and that mixed findings have been reported, particularly, when combat exposure has been applied as a general measure, ie, not distinguishing between different types of combat exposure. Thus, while the meta-analysis estimated a nonsignificant association between overall measures for combat exposure and SA, it did find a significant correlation to SA among those specifically exposed to killing or atrocity. ${ }^{12}$ One study ${ }^{13}$ found that killing enemies and not being able to prevent death and injury were linked to general psychological distress and SA. Deployment in itself should not be considered as a proxy for combat exposure, and it is possible that specific types of perceived danger influence suicidal behavior rather than combat exposure in general. It has previously been shown that (1) engaging in combat, ie, combat exposure, and (2) being witness to acts of war and being unable to prevent death and injury, ie, witnessing consequences of 


\section{Clinical Points}

- Information on the relationship between level of perceived exposure to danger during military deployment and postdeployment risk of suicide attempt is sparse.

- High level of perceived exposure to danger increased the risk for suicide attempt, but posttraumatic stress disorder (PTSD) and/or depression fully explained the association.

- This study suggests that better psychological follow-up of military personnel identified as having PTSD and/or depression may be warranted.

war, represent two distinctively different types of adversities for deployed personnel. ${ }^{14}$ Still, there is little evidence on the association between the main measure of perceived danger, which combat exposure is counted to be, and suicidal behavior, measured as SA. ${ }^{12,15}$ Yet, whether these two factors have different associations to SA remains to be examined.

Our study expands upon prior research by examining the association between specific combat experiences and post-deployment SA. Most studies have used self-reported information on suicide attempt, which may be subject to recall and information bias. ${ }^{16,17}$ Using register data may limit such biases, ${ }^{18}$ and the use of the unique Danish registers therefore gives us the rare opportunity to conduct a complete sampling of suicide attempts. To our knowledge a large-scale national cohort-based epidemiologic study comparing specific combat experiences and post-deployment SA has not been carried out before.

Having questionnaire data both on perceived combat exposure and on witnessing the consequences of war allowed us to examine whether being deployed may include traumatic and stressful experiences that are not related directly to combat (witnessing of non-combat atrocities) ${ }^{19,20}$ Therefore, the aim of the present study was (1) to evaluate possible associations between rating scale subscales measuring perceived exposure to danger, ie, combat exposure and witnessing consequences of war, and risk of post-deployment SA among Danish military personnel and (2) to determine whether post-deployment mental health problems (PTSD and/or depression) mediated this association. On the basis of conflicting evidence regarding combat exposure and risk of suicide attempt, we hypothesized that differentiating between combat exposure and witnessing consequences of war would contribute to the understanding of the association between perceived exposure to danger and risk of suicide attempt. We, furthermore, expected that both variables-combat exposure and witnessing consequences of war-would increase the risk of suicide attempt and that PTSD and/ or depression would influence the association between perceived exposure to danger either through moderation or through mediation.

\section{METHODS}

A cohort study design was applied. Questionnaire data collected among Danish Army military personnel ${ }^{21}$ were linked to the following national registers, administered by Statistic Denmark: the Danish Civil Registration System, ${ }^{22}$ National Patient Register, ${ }^{23}$ and Psychiatric Central Research register. ${ }^{24}$ Using a unique civil registration number (CRN), ${ }^{22}$ data on all Danish residents could be linked on an individual level across data sources. The study was approved by the Danish Data Protection Agency. As the study was based solely on registry and questionnaire data, no approval from the Committee on Health Research Ethics was needed.

\section{Subjects}

The study population consisted of Danish Army military personnel who (1) returned from deployment between 1998 and 2016 and (2) completed the Psychological Reactions following International Missions (PRIM) ${ }^{25}$ questionnaire. The mean response rate of the PRIM is $65.2 \%$, resulting in 21,102 completed questionnaires from 13,990 formerly deployed personnel, as some were deployed multiple times. ${ }^{25}$ Of the total 13,990 respondents, 612 were excluded due to missing values for the PRIM, 643 were excluded due to migration, and 517 were excluded due to multiple PRIM questionnaires completed during the same calendar year and no indication of which questionnaire matched which deployment or questionnaires answered outside the study period. For personnel deployed several times, we opted to include the latest PRIM response from each individual. As a result, data on 12,218 Danish Army military personnel deployed between 1997 and 2016 were included in the analysis. For all participants, we had information on the pattern of deployments, including the start and end dates. These data were retrieved from the Danish Veterans Centre deployment database.

\section{Measures}

Perceived exposure to danger. The PRIM questionnaire contains 10 items related to perceived danger during deployment (Supplementary Table 1). Of particular interest are two subscales, the Exposure to Danger and Combat subscale (EDCS, focusing on combat exposure) and the Witnessing the Consequences of War subscale (WCWS, focusing on witnessing consequences of war), which have been shown to capture two distinct aspects of deployment. ${ }^{14}$

Suicide attempt. The outcome of interest, SA, was identified from the National Patient Register $^{23}$ and the Psychiatric Central Research register. ${ }^{24}$ Using the International Classification of Diseases (ICD), Tenth Revision (ICD-10) codes, SA was defined by the commonly used Danish register-based algorithm ${ }^{26}$ : X60-X84 or when the reason for contact was listed as $\mathrm{SA}$, and all hospitalizations for which a main diagnosis indicated an intoxication (T39, T42, T43, and T58). Although a combination of the diagnoses of intoxication and psychiatric conditions is currently included in the Danish register-based algorithm, it was not included in the present study because Gasse et $\mathrm{al}^{26}$ recently found the positive predictive value for SA to be low in this category. For codes given prior to 1994, the 
equivalent $I C D-8$ codes were used. The primary outcome was included in the analyses as a binary variable-SA in registers (yes/no) - but also assessed as the exact date of SA, allowing us to estimate the time at risk (time to SA).

Measures of PTSD, depression, and social support. The PRIM questionnaire includes subscales related to PTSD symptoms and depression. ${ }^{27,28}$ The PRIM-PTSD scale consists of 12 items that assess symptoms of PTSD over the preceding 3 months and reflects PTSD symptoms as defined in the Diagnostic and Statistical Manual for Mental Disorders, Fourth Edition. ${ }^{29}$ This scale has been validated against the PTSD Checklist-Civilian Version IV (PCL-C). ${ }^{28}$ Likewise, the raw scores of a subscale, PRIM-depression, were used as a measure of depression and have been validated against the Beck Depression Inventory. ${ }^{27,30,31}$ The existence of PRIMdefined PTSD and/or PRIM-defined depression, based on the cutoff scores, were merged into the dichotomized variable "PTSD/depression," as some of the identified symptoms measured in the questionnaire could be indicative of either of the two disorders, which are known to co-occur ${ }^{8}$ and have both been found to be associated with SA. ${ }^{32-34}$

In addition, a score for perceived social support during and after deployment was calculated (Supplementary Table 2). The Cronbach $\alpha$ for this scale was acceptable (0.71). ${ }^{35}$

Covariates. Data on sociodemographic characteristics, ie, sex (male/female) and age at response ( $\leq 36,>36$ years), as well as deployment-related variables, ie, military rank (private, non-commissioned officer, officer, other [civilians, eg, medical personnel, legal personnel]), repatriated (yes/no), and previous deployment (yes/no), were extracted from the PRIM database and the Danish Veterans Centre deployment database. Any previous contact with the psychiatric system, either inpatient or outpatient, was captured by a variable on pre-deployment psychiatric contact (yes/no).

Follow-up. Each participant entered the analysis on the date of the last homecoming if a PRIM questionnaire had been completed 6 months after. All of the variables from the PRIM questionnaire (eg, those related to combat exposure and PTSD/depression) are obtained at approximately 6 months after homecoming, and the follow-up time starts at homecoming date +180 days. Participants were followed until the date of SA, date of death, date of emigration, date of the beginning of a new deployment without a corresponding PRIM response, or December 31, 2016. This allowed us to include those with an SA before the latest deployment with a completed PRIM questionnaire and adjust for predeployment SA.

\section{Statistical Analysis}

Descriptive statistics were used to show the sociodemographic characteristics and deployment-related variables for those with or without a post-deployment SA. Kaplan-Meier curves stratified by combat exposure and witnessing consequences of war were constructed to assess the time to SA from the latest homecoming. We calculated hazard ratios (HRs) with $95 \%$ confidence intervals (CIs) to assess the univariate and multivariate associations between
Table 1. Characteristics of Danish Military Personnel ( $n=12,218)$ According to Suicide Attempt After Homecoming of the Last Deployment ${ }^{\mathrm{a}}$

\begin{tabular}{|c|c|c|c|}
\hline Variable & $\begin{array}{l}\text { No Suicide } \\
\text { Attempt } \\
\text { After Last } \\
\text { Deployment }\end{array}$ & $\begin{array}{c}\text { Suicide } \\
\text { Attempt } \\
\text { After Last } \\
\text { Deployment }\end{array}$ & $\begin{array}{l}P \text { Value } \\
\text { ( } t \text { test or } \\
X^{2} \text { test) }\end{array}$ \\
\hline Total sample & $12,135(99.3)$ & $83(0.7)$ & $<.001$ \\
\hline Male & $11,386(93.8)$ & $80(96.4)$ & .33 \\
\hline Age $\leq 36$ y at last deployment & $9,477(78.1)$ & $75(90.4)$ & .01 \\
\hline $\begin{array}{l}\text { Pre-deployment psychiatric } \\
\text { diagnosis }\end{array}$ & $215(1.77)$ & 7 (8.43) & $<.001$ \\
\hline Pre-deployment suicide attempt & $172(1.41)$ & $0(0)$ & .29 \\
\hline Previous deployment(s) & $5,630(46.4)$ & $37(44.6)$ & .91 \\
\hline $\begin{array}{l}\text { Private military rank during } \\
\text { deployment }\end{array}$ & $7,071(58.3)$ & $67(80.7)$ & $<.001$ \\
\hline Repatriated & 699 (5.76) & $9(10.8)$ & .05 \\
\hline $\begin{array}{l}\text { Post-deployment PTSD and/or } \\
\text { depression }\end{array}$ & $1,455(12.0)$ & $24(28.9)$ & $<.001$ \\
\hline $\begin{array}{l}\text { EDCS score (combat exposure), } \\
\text { mean (SD) }\end{array}$ & $9.71(3.06)$ & $10.27(2.9)$ & $<.001$ \\
\hline $\begin{array}{l}\text { WCWS score (witnessing } \\
\text { consequences of war), } \\
\text { mean (SD) }\end{array}$ & $6.71(1.91)$ & $6.91(2.13)$ & .71 \\
\hline $\begin{array}{l}\text { Social support scale score, } \\
\text { mean (SD) }\end{array}$ & $15.4(2.86)$ & $14.66(3.23)$ & $<.001$ \\
\hline
\end{tabular}

avalues are show as $\mathrm{n}(\%)$ unless otherwise noted.

${ }^{\mathrm{b}}$ The EDCS assesses combat exposure with a total score ranging from 6 to 24 with the highest scores indicating the highest levels of exposure to combat and danger.

'The WCWS captures the extent of witnessing the consequences and hardships of war, with a total score ranging from 4 to 16 and a higher score indicating a greater level of witnessing the aftermath of battle.

${ }^{d}$ Social support scale is a score for perceived social support during and after deployment. It was calculated as the sum of 5 items in the PRIM questionnaire with a higher score indicating stronger social support. Abbreviations: EDCS = Exposure to Danger and Combat subscale, PTSD $=$ posttraumatic stress disorder, WCWS = Witnessing the Consequences of War subscale.

perceived danger during deployment and SA, using Cox proportional hazards regression analyses with time since the latest homecoming as the underlying time variable. Fulfillment of the proportional hazards assumption was checked for each independent variable included in the Cox proportional hazards regression models by testing for independence between scaled Schoenfeld residuals and time. The effect of perceived danger was investigated in the analyses using the continuous versions of the EDCS (combat exposure) and WCWS (witnessing consequences of war). First, we ran univariable models showing the association between SA and combat exposure and witnessing consequences of war, respectively. Next, in multivariable models, we adjusted the association between combat exposure and witnessing consequences of war and SA for sex, age group, previous deployment, social support, and pre-deployment psychiatric contact. We had planned to adjust for pre-deployment SA; however, it was found to be a perfect classifier, as none of those with post-deployment SA had a SA before and therefore not possible to include in the model. Model 1 included combat exposure, witnessing consequences of war, sex, age, previous deployment, social support, and pre-deployment psychiatric contact. Model 2 included sex, age, and those confounders with $P<.10$ in model 1 . 
A.

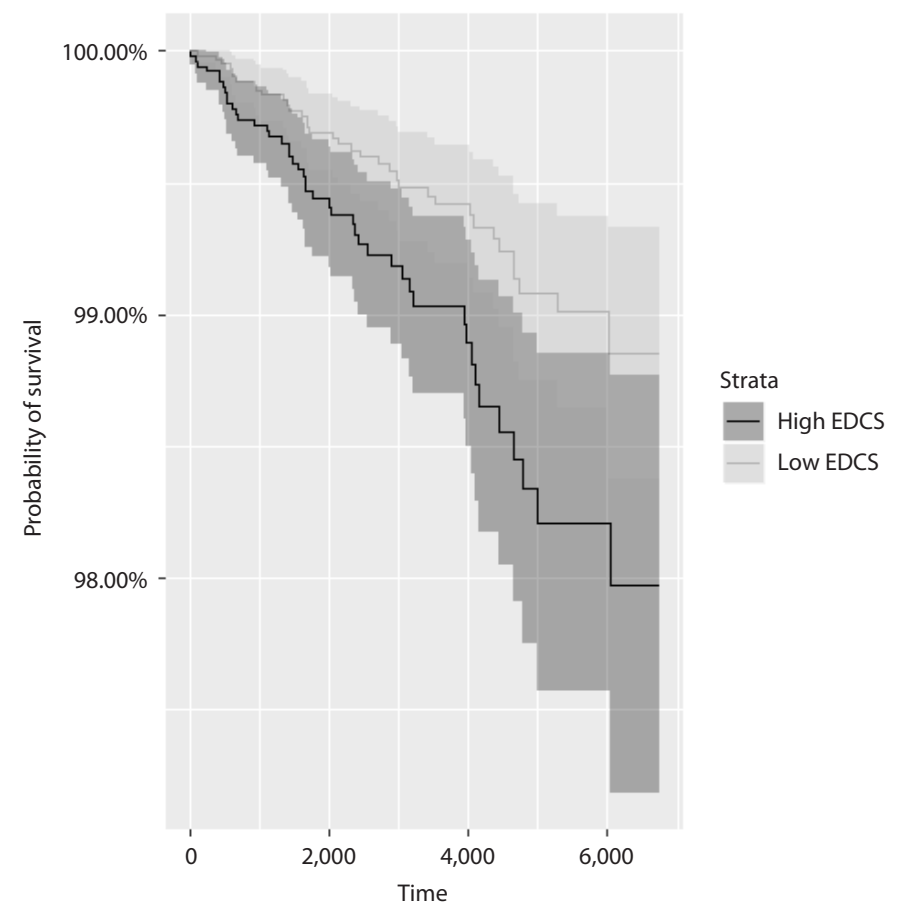

B.

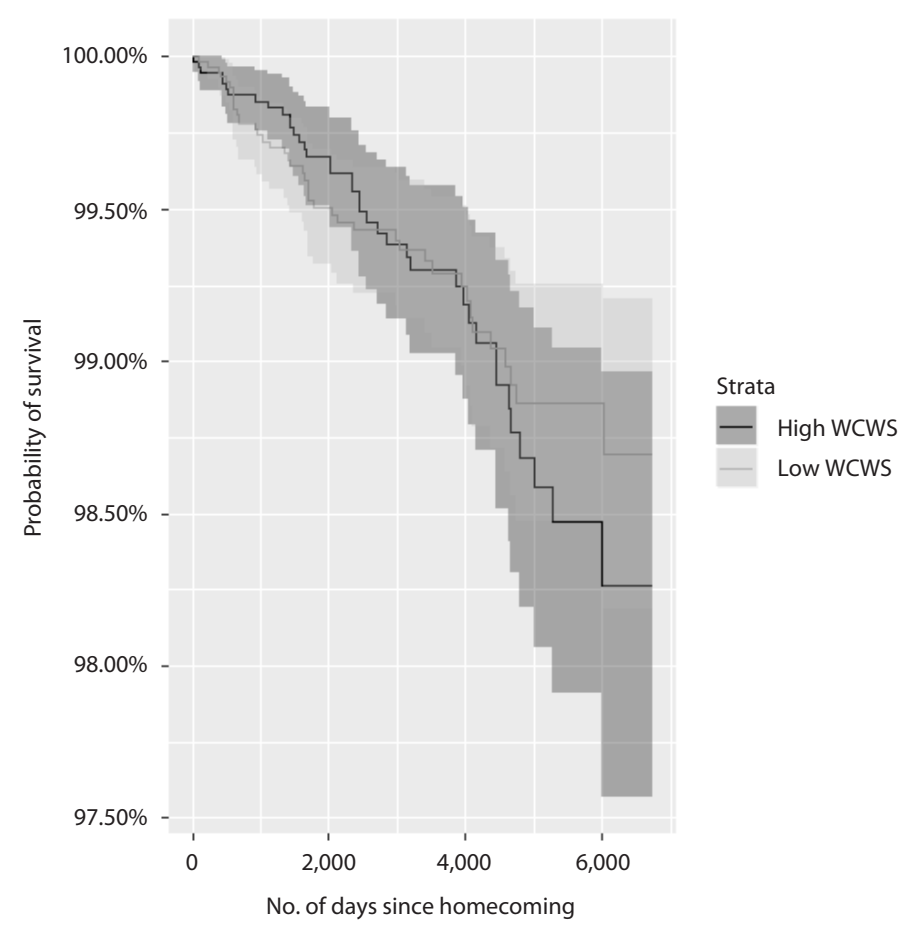

Abbreviation: EDCS = Exposure to Danger and Combat subscale, WCWS = Witnessing the Consequences of War subscale.
We examined the possible influence of PTSD/ depression on the association between combat exposure and SA: effect-measure modification was tested by introducing the interaction term between combat exposure and PTSD/depression in model 2. In case of no interaction, a mediation analysis was planned using a Sobel test with the product of coefficients approach including standardized regression coefficients allowing for a binary mediator (PTSD/depression). ${ }^{36,37}$ Statistical analyses were performed using SAS version 9.2 (SAS Institute, Inc; Cary, North Carolina) and R version 3.4.1 (R Development Core Team; Vienna, Austria). The nominal statistical significance level was set at .05 .

\section{RESULTS}

In total, 12,218 military personnel were followed over a mean of 8.58 years. During follow-up, 83 persons were hospitalized at least once for SA, corresponding to a rate of 81.4 (95\% CI, 73.2-91.2) per 100,000 person-years. Those with an episode of SA were younger, had lower military rank, were more often repatriated, had lower social support, had higher combat exposure scores, and had more often received a pre-deployment psychiatric diagnosis. Personnel with SA were also more likely to have had post-deployment PTSD and/or depression (PTSD/depression) (Table 1). In total, 86 persons died during the follow-up period, equivalent of an incidence rate (IR) of 84.4 ( $95 \%$ CI, 67.6-104.9) per 100,000 person-years. Of these, 13 died by suicide $(\mathrm{IR}=12.75 ; 95 \% \mathrm{CI}, 7.33-22.02)$. The majority died of neoplasms $(n=24)$ and cardiovascular disease $(\mathrm{n}=16)$. Among personnel with post-deployment SA, all deaths were by suicide $(n=4)$. The KaplanMeier curves in Figure 1 show the time to SA by combat exposure (Figure 1A) and witnessing consequences of war (Figure 1B). The log rank test showed that there was significant difference between the low and high level of combat exposure $(P=.007)$ and risk of SA, whereas there was no significant difference for witnessing consequences of war.

The univariate models showed a significant association between combat exposure and the risk of SA (HR $=1.10 ; 95 \% \mathrm{CI}, 1.02-1.18)$ and a nonsignificant association between witnessing consequences of war and the risk of $\mathrm{SA}(\mathrm{HR}=1.08$; 95\% CI, 0.96-1.21) (Table 2). As no association was found for witnessing consequences of war in the univariate analysis, this measure was omitted from subsequent analyses and was included only as covariate in the multivariate analyses of combat exposure. In the multivariable Cox regression analyses, model 1 included combat exposure, witnessing consequences of war, sex, age, previous deployment, social support, and pre-deployment 
as a preventive factor of SA following deployment. Social support is associated with a lower risk of PTSD in both the general population and military settings. ${ }^{42}$ In a metaanalysis conducted by Xue et al, ${ }^{16}$ unit support was found to decrease the post-deployment risk of PTSD by $41 \%$ (odds ratio $=0.59 ; 95 \%$ CI, 0.45-0.78). High levels of social care and support may foster feelings of self-reliance and selfsecurity among military personnel; these feelings protect against PTSD. ${ }^{16}$ A meta-analysis examining risk factors for PTSD among trauma-exposed adults ${ }^{42}$ showed that lack of social support had somewhat stronger effects than pretrauma factors on the development of PTSD. In our study, the Cox regression analyses demonstrated that having a predeployment psychiatric diagnosis increases the risk of SA by almost 6 times. However, SAs are challenging to predict, which underscores the need for multilevel prevention. ${ }^{43}$ Another approach could be to use preexisting clinical psychiatric diagnosis as recorded in the unique Danish registers as a screening tool. However, there might be negative consequences regarding screening in this setting, as some may fear that seeking help would eventually harm their career $^{44}$ and therefore lead to reduced care-seeking for mental health problems. ${ }^{45} \mathrm{~A}$ recent study by Ursano et $\mathrm{al}^{46}$ investigated which factors were associated with suicidal ideation in the past-30-day period among US army soldiers at the midpoint of their deployment in Afghanistan. Soldiers reporting 30-day suicidal ideation at mid-deployment were nearly 44 times more likely than those without suicidal ideation to subsequently attempt suicide through the first year after returning from deployment. Therefore, screening for suicidal ideation in deployed soldiers may be an effective strategy for identifying those at risk of SA.

The prevalences of suicide and SAs among Danish Army military personnel have in previous studies been found to be lower or at the same level as in the general Danish population. ${ }^{47,48}$ Suicide rates among service members of the US Army have historically been lower than that of the general US population. However, that has changed in recent years, and the suicide rate of US service members is now higher than that of the general population. ${ }^{11}$ Furthermore, the military suicide rate in the United States has steadily risen to a record high since the start of combat operations in Afghanistan and Iraq. ${ }^{12}$ These findings emphasize the need for continued monitoring of suicidal behavior among Danish Army military personnel even though the rates are currently low. Some of the contributing factors may be the existing program in the Danish Defense, which entails screening of military personnel prior to international deployment as well as having psychologists follow a team within the Army from before deployment to during deployment and post-deployment. In addition, a universal health care system in Denmark includes free access to mental health care.

Our study finding that combat exposure, fully mediated by PTSD/depression, increases the risk of post-deployment SA emphasizes that personnel with symptoms of PTSD and/ or depression should be subject to closer monitoring than the rest of the military personnel. SA is known to be one of the strongest predictors of death by suicide because of the robust relationship between SA and death by suicide. ${ }^{49,50}$ A study of 37-year longitudinal data ${ }^{51}$ showed that the elevated risk of suicide after an SA persists. This result is supported by our finding that all deaths among personnel with post-deployment SA were by suicide.

By linking self-administered questionnaires with register data, we were able to obtain complete information on all hospitalized cases of attempted suicide. Although SA is underreported in the Danish hospital registers, ${ }^{52-54}$ the national and complete coverage, avoiding recall and reporting bias, is a strength of this study. Furthermore, we have a long follow-up period, and the study population is not restricted to one specific mission or war, but includes all Danish military personnel who had been deployed in the study period and who had answered the questionnaire regarding perceived exposure to danger during deployment. As another strength, it should be noted that we used validated scales for PTSD, depression, combat (combat exposure), and witnessing consequences of war.

One limitation is that not all deployed personnel completed the PRIM questionnaire; therefore, we were unable to conduct an assessment of the $34.8 \%$ of personnel who did not respond. We included in our cohort only information based on the latest deployment with a PRIM response, which means that there could have been previous deployment (or deployments) that may be a strong predictor in itself for SA, and also there might have been lower or higher combat exposure from previous deployments. At the same time, it may be assumed that previously deployed personnel are more resilient, as they are able to re-deploy and therefore may have a lower risk of SA. However, in the subanalyses, in which we adjusted for previous deployment, the estimate of SA did not differ. In this study, we examined PTSD and depression as one variable. The conditions are frequently comorbid, and there is some symptom overlap. However, when it comes to clinical implications of the study in terms of recommendations for increased screening and early intervention, it may be a disadvantage to not distinguish between these conditions. Finally, we cannot exclude that important extraneous variables could have affected the results, such as exposure to child abuse $\mathrm{e}^{55}$ and witnessing moral injuries. ${ }^{56}$ In our study, we did not have access to this kind of information.

\section{Clinical Implications}

The knowledge gained in the present study may assist clinicians in better follow-up of military personnel identified as having PTSD and/or depression, as these individuals are at increased risk of SA, regardless the amount and type of combat exposure to which they have been exposed. It may help both clinicians and leadership in identifying and treating those at increased risk of postdeployment suicidal behavior. However, there will still be others than those with PTSD and/or depression who are at risk of SA. 


\section{CONCLUSION}

The relation between combat exposure, PTSD and/ or depression, and risk of SA is complex. We found that higher levels of perceived exposure to danger and combat were associated with increased risk of post-deployment SA, including when social support during the deployment and preexisting psychiatric diagnoses were taken into account. This association was fully mediated by mental health problems (depression and/or PTSD) reported shortly after deployment, indicating the importance of targeting symptoms of PTSD/depression among Danish army military personnel to diminish risk of SA among those with combat exposure.
Submitted: January 14, 2021; accepted March 9, 2021.

Published online: October 12, 2021.

Potential conflicts of interest: None.

Funding/support: This study was supported by Soldaterlegatet with financial support from Tryg (grant ID 119562), Lundbeck, NovoNordisk, and the Aase and Ejnar Danielsen Foundation.

Role of the sponsor: The funders of the study had no role in design and conduct of the study; collection, management, analysis, and interpretation of the data; and preparation, review, or approval of the manuscript or the decision to submit for publication.

Additional information. The Danish Veterans Centre deployment database is owned by the Danish Veterans Centre, organized under the Danish Ministry of Defence Personnel Agency. Parties interested in obtaining these data can contact the Danish Veterans Centre and apply for access to the data.

Supplementary material: Available at PSYCHIATRIST.COM.

\section{REFERENCES}

1. Lento RM, Carson-Wong A, Green JD, et al. Is suicidal behavior in mood disorders altered by comorbid PTSD? Crisis. 2019;40(1):62-66.

2. Bryan CJ, Hernandez AM, Allison S, et al. Combat exposure and suicide risk in two samples of military personnel. J Clin Psychol. 2013:69(1):64-77.

3. Nock MK, Stein MB, Heeringa SG, et al; Army STARRS Collaborators. Prevalence and correlates of suicidal behavior among soldiers: results from the Army Study to Assess Risk and Resilience in Servicemembers (Army STARRS). JAMA Psychiatry. 2014;71(5):514-522.

4. Bryan CJ, Cukrowicz KC, West CL, et al. Combat experience and the acquired capability for suicide. J Clin Psychol. 2010;66(10):1044-1056.

5. Kang HK, Bullman TA. Risk of suicide among US veterans after returning from the Iraq or Afghanistan war zones. JAMA. 2008;300(6):652-653.

6. Sareen J, Afifi TO, Taillieu T, et al. Trends in suicidal behaviour and use of mental health services in Canadian military and civilian populations. CMAJ. 2016:188(11):E261-E267.

7. Jakšić N, Margetić BA, Marčinko D. Comorbid depression and suicide ideation in patients with combat-related PTSD: the role of temperament, character, and trait impulsivity. Psychiatr Danub. 2017;29(1):51-59.

8. Rytwinski NK, Scur MD, Feeny NC, et al. The co-occurrence of major depressive disorder among individuals with posttraumatic stress disorder: a meta-analysis. J Trauma Stress. 2013:26(3):299-309.

9. Gray GC, Chesbrough KB, Ryan MAK, et al; Millennium Cohort Study Group. The Millennium Cohort Study: a 21-year prospective cohort study of 140,000 military personnel. Mil Med. 2002;167(6):483-488.

10. Ursano RJ, Colpe LJ, Heeringa SG, et al; Army
STARRS collaborators. The Army Study to Assess Risk and Resilience in Servicemembers (Army STARRS). Psychiatry. 2014;77(2):107-119.

11. Nock MK, Deming CA, Fullerton CS, et al. Suicide among soldiers: a review of psychosocial risk and protective factors. Psychiatry. 2013;76(2):97-125.

12. Bryan CJ, Griffith JE, Pace BT, et al. Combat exposure and risk for suicidal thoughts and behaviors among military personnel and Veterans: a systematic review and metaanalysis. Suicide Life Threat Behav. 2015:45(5):633-649.

13. Fontana A, Rosenheck R, Brett E. War zone traumas and posttraumatic stress disorder symptomatology. J Nerv Ment Dis. 1992;180(12):748-755.

14. Karstoft K-I, Nielsen T, Nielsen ABS. Perceived danger during deployment: a Rasch validation of an instrument assessing perceived combat exposure and the witnessing of combat consequences in a war zone. Eur J Psychotraumatol. 2018;9(1):1487224.

15. Sareen J, Afifi TO, Taillieu T, et al. Deploymentrelated traumatic events and suicidal behaviours in a nationally representative sample of Canadian armed forces personnel. Can J Psychiatry. 2017;62(11):795-804.

16. Xue C, Ge Y, Tang B, et al. A meta-analysis of risk factors for combat-related PTSD among military personnel and veterans. PLoS One. 2015;10(3):e0120270.

17. Nissen LR, Stoltenberg C, Nielsen ABS, et al. Danish Gulf War Veterans revisited: no evidence of increased sickness absence or reduced labor market outcome after deployment to the Persian Gulf. Mil Med. 2016;181(11):e1644-e1649.

18. Johannesdottir SA, Horváth-Puhó E, Ehrenstein $V$, et al. Existing data sources for clinical epidemiology: the Danish National Database of Reimbursed Prescriptions. Clin Epidemiol. 2012;4:303-313.

19. King LA, King DW, Vogt DS, et al. Deployment risk and resilience inventory: a collection of measures for studying deployment-related experiences of military personnel and Veterans. Mil Psychol. 2006;18(2):89-120.

20. Polusny MA, Kumpula MJ, Meis LA, et al. Gender differences in the effects of deployment-related stressors and predeployment risk factors on the development of PTSD symptoms in National Guard Soldiers deployed to Iraq and Afghanistan. J Psychiatr Res. 2014;49(1):1-9.

21. The Danish Veterans Centre. www.veteran. forsvar.dk.

22. Pedersen CB, Gøtzsche H, Møller JO, et al. The Danish Civil Registration System: a cohort of eight million persons. Dan Med Bull. 2006;53(4):441-449.

23. Schmidt M, Schmidt SAJ, Sandegaard JL, et al. The Danish National Patient Registry: a review of content, data quality, and research potential. Clin Epidemiol. 2015;7:449-490.

24. Mors O, Perto GP, Mortensen PB. The Danish Psychiatric Central Research Register. Scand Public Health. 2011;39(7 suppl):54-57.
25. Nissen LR, Karstoft K-I, Vedtofte MS, et al. Cognitive ability and risk of post-traumatic stress disorder after military deployment: an observational cohort study. BJPsych Open. 2017;3(6):274-280.

26. Gasse C, Danielsen AA, Pedersen MG, et al. Positive predictive value of a register-based algorithm using the Danish National Registries to identify suicidal events. Pharmacoepidemiol Drug Saf. 2018;27(10):1131-1138.

27. Karstoft K-I, Nielsen ABS, Nielsen T. Assessment of depression in veterans across missions: a validity study using Rasch measurement models. Eur J Psychotraumatol. 2017;8(1):1326798.

28. Karstoft K-I, Andersen SB, Nielsen ABS Assessing PTSD in the military: validation of a scale distributed to Danish soldiers after deployment since 1998. Scand J Psychol. 2017;58(3):260-268.

29. American Psychiatric Association. Diagnostic and Statistical Manual for Mental Disorders. Fourth Edition. Washington, DC: American Psychiatric Association; 1994.

30. Nissen LR, Karstoft K-I, Vedtofte MS, et al. Lowlevel cognitive ability in young adulthood and other risk factors of depression in an observational cohort study among deployed Danish soldiers. Soc Psychiatry Psychiatr Epidemiol. 2019;54(4):497-506.

31. Beck AT, Ward $\mathrm{CH}$, Mendelson $\mathrm{M}$, et al. An inventory for measuring depression. Arch Gen Psychiatry. 1961;4(6):561-571.

32. Pompili M, Sher L, Serafini G, et al. Posttraumatic stress disorder and suicide risk among veterans: a literature review. J Nerv Ment Dis. 2013;201(9):802-812

33. Melhem NM, Porta G, Oquendo MA, et al. Severity and variability of depression symptoms predicting suicide attempt in highrisk individuals. JAMA Psychiatry. 2019;76(6):603-613.

34. Dillon KH, Cunningham KC, Neal JM, et al; VA Mid-Atlantic MIRECC Workgroup. Examination of the indirect effects of combat exposure on suicidal behavior in veterans. J Affect Disord. 2018;235:407-413.

35. Cortina JM. What is coefficient alpha? an examination of theory and applications. J Appl Psychol. 1993;78(1):98-104.

36. Fairchild AJ, McDaniel HL. Best (but oftforgotten) practices: mediation analysis. Am J Clin Nutr. 2017;105(6):1259-1271.

37. Mackinnon DP, Cox MC. Mediation analysis and categorical variables: the final frontier. J Consum Psychol. 2012;22(4):600-602.

38. Fear NT, Jones M, Murphy D, et al. What are the consequences of deployment to Iraq and Afghanistan on the mental health of the UK armed forces? a cohort study. Lancet. 2010;375(9728):1783-1797.

39. Gates MA, Holowka DW, Vasterling JJ, et al. Posttraumatic stress disorder in veterans and military personnel: epidemiology, screening, and case recognition. Psychol Serv. 2012;9(4):361-382.

40. Taal ELM, Vermetten $E$, van Schaik DAJF, et al. Do soldiers seek more mental health care after 


\section{Vedtofte et al}

deployment? analysis of mental health consultations in the Netherlands Armed Forces following deployment to Afghanistan. Eur J Psychotraumatol. 2014:5(1):1-10.

41. Osório C, Jones N, Jones $\mathrm{E}$, et al. Combat experiences and their relationship to posttraumatic stress disorder symptom clusters in UK military personnel deployed to Afghanistan. Behav Med. 2018;44(2):131-140.

42. Brewin CR, Andrews B, Valentine JD. Metaanalysis of risk factors for posttraumatic stress disorder in trauma-exposed adults. J Consult Clin Psychol. 2000;68(5):748-766.

43. Belsher BE, Smolenski DJ, Pruitt LD, et al. Prediction models for suicide attempts and deaths: a systematic review and simulation. JAMA Psychiatry. 2019;76(6):642-651.

44. Hoge CW, Castro CA, Messer SC, et al. Combat duty in Iraq and Afghanistan, mental health problems, and barriers to care. NEngl J Med. 2004;351(1):13-22.

45. Stoltenberg CDG, Nissen LR, Nielsen ABS, et al. Effect of predeployment psychiatric diagnoses on postdeployment long-term sickness absence and mental health problems among Danish military personnel. J Trauma Stress. 2020;33(3):285-295.

46. Ursano RJ, Herberman Mash HB, Kessler RC, et al. Factors associated with suicide ideation in US Army soldiers during deployment in Afghanistan. JAMA Netw Open. 2020;3(1):e1919935.

47. Ejdesgaard BA, Zøllner L, Jensen BF, et al. Risk and protective factors for suicidal ideation and suicide attempts among deployed Danish soldiers from 1990 to 2009. Mil Med. 2015;180(1):61-67.

48. Vedtofte MS. Selvmord Blandt Veteraner: 1992-2014. Ringsted, Denmark: Veterancentret; 2014.

49. Brown GK, Beck AT, Steer RA, et al. Risk factors for suicide in psychiatric outpatients: a 20-year prospective study. J Consult Clin Psychol. 2000;68(3):371-377.

50. Joiner TEJ Jr, Conwell Y, Fitzpatrick KK, et al. Four studies on how past and current suicidality relate even when "everything but the kitchen sink" is covaried. J Abnorm Psychol. 2005;114(2):291-303.

51. Suominen K, Isometsä E, Suokas J, et al. Completed suicide after a suicide attempt: a 37-year follow-up study. Am J Psychiatry. 2004;161(3):562-563.

52. Nordentoft M. Prevention of suicide and attempted suicide in Denmark: epidemiological studies of suicide and intervention studies in selected risk groups. Dan Med Bull. 2007:54(4):306-369.

53. Helweg-Larsen K. Suicide in Denmark. University of Southern Denmark. 2006. https:// www.sdu.dk/da/sif/rapporter/2006/ selvmord_i_danmark

54. Reuter Morthorst B, Soegaard B, Nordentoft M, et al. Incidence rates of deliberate self-harm in Denmark 1994-2011. Crisis. 2016;37(4):256-264.

55. Afifi TO, Taillieu T, Zamorski MA, et al. Association of child abuse exposure with suicidal ideation, suicide plans, and suicide attempts in military personnel and the general population in Canada. JAMA Psychiatry. 2016;73(3):229-238.

56. Zerach G, Levi-Belz Y. Intolerance of uncertainty moderates the association between potentially morally injurious events and suicide ideation and behavior among combat Veterans. J Trauma Stress. 2019:32(3):424-436.

Editor's Note: We encourage authors to submit papers for consideration as a part of our Focus on Suicide section. Please contact Philippe Courtet, MD, PhD, at pcourtet@psychiatrist.com. 


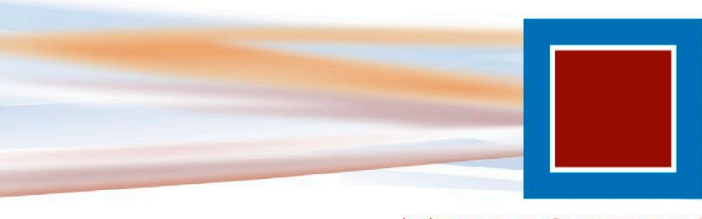

THE JOURNAL OF

CLINICAL PSYCHIATRY

THE OFFICIAL JOURNAL OF THE AMERICAN SOCIETY OF CLINICAL PSYCHOPHARMACOLOGY

\section{Supplementary Material}

Article Title: Combat Exposure and Risk of Suicide Attempt Among Danish Army Military Personnel

Author(s): $\quad$ Mia S. Vedtofte, PhD; Andreas F. Elrond, PhD; Annette Erlangsen, PhD;

Anni B. S. Nielsen, PhD; Christian D. G. Stoltenberg, MSc; Jacob L. Marott, MSc;

Lars R. Nissen, MD; and Trine Madsen, PhD

DOI Number: https://doi.org/10.4088/JCP.20m13251

\section{List of Supplementary Material for the article}

1. Iable 1 Items in the original 18-items PRIM Combat Stress Exposure Scale

2. Table 2 Items in social support scale

\section{Disclaimer}

This Supplementary Material has been provided by the author(s) as an enhancement to the published article. It has been approved by peer review; however, it has undergone neither editing nor formatting by in-house editorial staff. The material is presented in the manner supplied by the author. 
Supplementary Table 1. Items in the original 18-items PRIM Combat Stress Exposure Scale

During the deployment, did you experience...:

1. Getting wounded or were you injured during the mission?

2. Seeing any of your fellow soldiers get wounded, injured or die?

3. Ever being held captive or held back by the enemy against your will?

4. Any of your fellow soldiers being held captive or held back by the enemy against their will?

5. Being threatened with a weapon?*§

6. Being shot at?*§

7. Firing your weapon?

8. The camp being under enemy fire?

9. Being in areas with roadside bombs or mines?* $\S$

10. Passing areas with combat activities?*§

11. Receiving threats from the involved?

12. Aggressive behavior from the locals?* $\S$

13. Witnessing distress among the locals?*^

14. Seeing dead people?*^

15. Seeing wounded people?*^

16. Being witness to assaults on civilians?*^

17. The involved preventing you from carrying out your mission?

18. Insufficient reinforcement or relief of your unit?*§

Note. The Scale is originally in Danish and has been translated by the authors who made the validation study of the scale ${ }^{1}$

* Included in Danger-Injury Scale. ${ }^{\wedge}$ Included in Witnessing Consequences of War subscale (witnessing consequences of war) \& Included in the Exposure to Danger and Combat subscale (combat exposure). All items had four response categories (1=never, $2=$ seldom, $3=$ fairly often, $4=$ almost daily).

\footnotetext{
${ }^{1}$ Karstoft K-I, Nielsen T, Nielsen ABS. Perceived danger during deployment: a Rasch validation of an instrument assessing perceived combat exposure and the witnessing of combat consequences in a war zone. Eur J Psychotraumatol. 2018;9(1):1487224.
} 
Supplementary Table 2. Items in social support scale

During the deployment, did you experience...:

1) In your group you showed interest in each other during deployment?

2) In your group you talked about unpleasant events experienced during deployment?

3) You were supported and encouraged by your closest superior during deployment?

When you think of the first period of time after homecoming, did you experience...:

4) You experienced substantial support from family/friends after homecoming Have you during the time from homecoming and until today, experienced the following...:

5) You could share your worries and problems with family and friends after homecoming

Note. The Scale is originally in Danish and has been translated by the authors. All items had four response categories (1=completely correct, 2=almost correct, 3=correct to some extent, 4=not correct) 